www.volsu.ru

DOI: http://doi.org/10.15688/nav.jvolsu.2016.1.7

UDC 930.26(470+571):903.53

LBC 63.48(2)-427.1

\title{
ANTONOV II BURIAL MOUND
}

\author{
Vladislav I. Mamontov \\ Volgograd State Socio-Pedagogical University, Volgograd, Russian Federation \\ Vasiliy V. Mataev \\ Archaeological expedition Ltd., Rostov Region, Russian Federation
}

\begin{abstract}
Three barrows were excavated in $10 \mathrm{~km}$ to the East from the Antonov village in the Oktyabrsky district of the Volgograd region. There was a burial of the early period carcass culture in the big mound. There were some bones of a sacrificial animal and buried pottery near the skeleton. Burials under mounds of small barrows belong to the late Sarmatian period. Local and imported ceramics, fragments of the waist belt buckles, chip of the bone plate were found here. These hills belong to the $2^{\text {th }}-3^{\text {th }}$ centuries.

Key words: Bronze Age, Pokrovskaya culture, timber-grave culture, Rigveda, early iron age, Late Sarmatian culture, burial, ceramics.
\end{abstract}

УДК 930.26(470+571):903.53

ББК 63.48(2)-427.1

\section{КУРГАННЫЙ МОГИЛЬНИК АНТОНОВ II}

\section{Владислав Иванович Мамонтов}

Волгоградский государственный социально-педагогический университет, г. Волгоград, Российская Федерация

\section{Василий Владимирович Матаев}

ООО «Археологическая экспедиция», Ростовская область, Российская Федерация

Аннотация. Три кургана раскопаны в 10 км на восток от поселка Антонов Октябрьского района Волгоградской области. В большом кургане находилось погребение раннего периода срубной культуры. Около скелета погребенного обнаружена керамика и кости жертвенного животного. Погребения под насыпями небольших курганов принадлежат поздним сарматам. Их сопровождали местная и импортная керамика, фрагменты портупейных пряжек, обломок костяной накладки. Относятся ко II-III векам.

Ключевые слова: эпоха бронзы, покровская культура, срубная культура, Ригведа, ранний железный век, позднесарматская культура, погребение, керамика.

Приволжский отряд ИИМК РАН и Донской экспедиции археологической лаборатории НИС ВГПУ в 1992 г. провел раскопки трех курганов (Антонов II) в зоне строительства шоссе Антонов - Васильевка. Их насыпи находились на пашне в 10 км на восток от пос. Антонов Октябрьского района Волгоградской области [Мамонтов, 1992, с. 13-18]. Ранее, в 1991 г., на северной окраине этого поселка была исследована группа курганов, также состоявшая из трех насыпей (Антонов I). Они располагались на краю высокой правой коренной террасе p. Аксай, левого притока р. Дон [Мамонтов, 1991, с. 16-29].

\section{Курган 1}

Насыпь кургана овальная. Длина 30 м, ширина 29 м, высота 2,12 м.

Погребение 1. Кости ребенка разбросаны глубокой пахотой. Находились на глубине 0,3 м от 0 отметки. На этом же уровне собрано несколько фрагментов толстостенного со- 
суда ручной лепки. Погребение относится к срубной культуре.

Погребение 2. Фрагменты скелета человека найдены в слое пахоты на глубине 0,34 м.

Погребение 3. Яма овальная, в северовосточной части ее были зафиксированы слои жердей, прутьев и куги, положенных по направлению СВ-Ю3. Яма ориентирована по линии восток-запад. Длина ямы 1,46 м, ширина 1,21 м, глубина 1,7 м. На уровне дна яма имела размеры $1,4 \times 1,17$ м. Все дно засыпано тонким слоем мела и охры.

Скелет мужчины 50-60 лет лежал головой на восток в сильно скорченном положении на правом боку. Кости рук согнуты в локтях так, что их кисти лежали на плечевых костях. На берцовых и пяточных костях видны слабые пятна красной охры. С этим погребением связан материковый выкид (рис. 1,1).

Сопровождающий инвентарь:

1. Фрагменты черноглиняного баночного сосуда лежали на подстилке у юго-западного края ямы. Глина в изломе темная, без заметных добавок. Диаметр устья 13,4 см, высота 10,4 см, диаметр дна 9,4 см. Край венчика направлен вовнутрь. На дне сосуда сохранилась толстая плотная масса серо-зеленого цвета с небольшой примесью темных крупиц (рис. 1,4).

2. Высокий биконический сосуд (верхняя часть тулова частично отбита) стоял на Ю3 краю ямы, на подстилке из куги. Глина в изломе темная без заметных примесей. На внутренней поверхности сосуда и на тулове отмечены следы копоти, нагара, следы грубого сглаживания. Выше ребра нанесен короткий горизонтальный ряд насечек острием. Край дна выделен линией, проведенной по сырой глине концом палочки. Диаметр венчика $21 \mathrm{~cm}$, высота сосуда 18,4 см, диаметр дна 9 см (рис. 2,3).

3. В засыпи ямы на глубине 0,52 м от края могилы, у юго-западной стенки, найден крупный фрагмент большого толстостенного глиняного кухонного горшка. Глина плотная темная с добавкой частиц мела. На внешней стороне тулова, у венчика, мелкозубчатым штампом нанесены отдельные углы с параллельными сторонами. На поверхности черепка видны пятна копоти и короткие риски, оставленные при «расчесывании» мелкозубчатым штампом. На внутренней поверхности - горизонтальные и вертикальные следы сглаживания - короткие проходы пучком травы. Реконструированный диаметр венчика $38 \mathrm{~cm}$ (рис. 2,1).

4. Фрагменты костей ног барана найдены в засыпи, на глубине 0,6 м от края ямы, в ее северо-восточном углу, на одном уровне с фрагментами глиняного сосуда (план 3 ).

5. Фрагменты глиняного сосуда собраны на дне ямы ближе к северо-восточному углу. Под дном сосуда - большое пятно красной охры. Сосуд имеет отогнутый наружу широкий край устья, закругленное сглаженное ребро и хорошо выделенное защипами дно. Ниже края венчика и по ребру проходят по две горизонтальные параллельные линии, выполненные мелкозубчатым штампом. Пространство между ними покрыто наклонными параллельными линиями (по две-три линии). Площадь между ними заполнена параллельными, слегка наклонными, линиями мелкозубчатого штампа. Ниже сглаженного ребра тем же приемом нанесены углы с 3-4 сторонами, параллельными друг другу. На пространстве у дна, с помощью наклонных ударов концом палочки по сырой глине, нанесены треугольники, вершинами вверх. На тулове заметны слабые вертикальные следы сглаживания. Внутри сосуда сохранились следы пригоревшей пищи. На тулове заметны пятна копоти. Диаметр венчика 17 см, высота сосуда 15,8 cм, диаметр дна 8,6 см (рис. 2,2).

Погребение относится к раннему периоду срубной культуры.

\section{Курган 2}

Диаметр насыпи 12 м, высота 0,41 м.

Погребение 1. Вход в яму имеет вид удлиненного овала, ориентированного по направлению С-Ю. Длина 2,16 м, ширина 0,64 м. В средней части ямы, на уровне 0,46 м, фиксировалось подовальное пятно с размерами $1,07 \times 0,72$ м, глубиной 0,67 м и шириной 0,4 м. Подбой находился в восточной стенке и был ориентирован также, как и входная яма. Высота ступеньки 0,4 м, высота свода 0,7 м и ширина подбоя 0,9 м. Ступенька посыпана пеплом и крупицами угля. В засыпи подбоя обнаружено короткое толстое бревно, которое шло по длине камеры. 
На дне ямы в вытянутом положении, на спине, головой на юг, лежал погребенный 40-45 лет. Его тело при размещении в подбое было изогнуто по дуге, вероятно, из-за высокого роста умершего. Кости рук вытянуты вдоль тела, череп лежал на правой стороне, лицевыми костями к стенке подбоя. Череп имеет следы прижизненной деформации (рис. 1,2).

Сопровождающий инвентарь:

1. Сероглиняная миска станковой работы стояла у левой руки. Край чаши наклонен вовнутрь. Внутренняя поверхность дна имеет в средней части небольшой подъем. Диаметр устья миски 20,8 см, высота 6,8 см, диаметр дна 7,2 см (рис. 2,5).

2. Расслоившиеся фрагменты черноглиняного лепного горшка лежали за затылком погребенного. Край короткого венчика отогнут наружу. Тулово округлое с пятном копоти. В глине заметна примесь песка. Диаметр венчика 12 см, высота сосуда 13 см, диаметр дна 6 см (рис. 3,1 ).

3. Сероглиняный кувшин стоял за затылком погребенного. Имеет высокую горловину с утолщенным краем венчика, реповидное приземистое тулово, узкое дно. Ручка овальная в сечении. У края венчика шла круговая прерывистая полоска, прочерченная концом палочки. Две линии, исполненные таким же приемом, проходили по основанию горловины и три линии - несколько выше широкой части тулова. Диаметр венчика 9,2 см, высота кувшина 16,2 см, диаметр дна 6 см (рис. 2,4).

4. Кости ног, ребра барана лежали в миске.

5. Фрагментированный однолезвийный железный нож найден в миске, среди костей барана. Сечение каплевидное, длина сохранившейся части 8,5 см. Наибольшая ширина лезвия 2 см. На черенке и лезвии заметны небольшие участки отпечатка ткани (рис. 3,3 ).

6. Фрагмент железного кольца обнаружен на дне ямы у миски. Диаметр 3,5 см (рис. 3,2).

7. Фрагментированная железная пряжка лежала у пяточных костей погребенного. Сечение стержня кольца округлое, на него надета петля язычка и прикреплен небольшой подпрямоугольный щиток. Длина изделия $3 \mathrm{~cm}$, диаметр кольца 2,2 см (рис. 2,6).

8. Фрагментированный железный крюк на портупее лежал рядом с пряжкой, между берцовыми костями погребенного. Кончик сломан, длина 3,1 см (рис. 2,7).

Погребение относится к позднесарматскому времени.

\section{Курган 3}

Диаметр кургана 24 м, высота 1,52 м. Северная пола разрушена кюветом.

Находка в насыпи 1: донная часть большого лепного сероглиняного сосуда со следами сглаживания на внутренней стороне. Глина плотная серая, с добавкой крупиц песка. Диаметр слегка прогнутого дна 14,2 см (рис. 3,8).

Находка в насыпи 2: два фрагмента венчика толстостенного сероглиняного сосуда. Край венчика немного направлен наружу (рис. 3,7 ).

Находка в насыпи 3: фрагменты черноглиняного тонкостенного сосуда, находились среди черепков дна сероглиняного сосуда. Край венчика отогнут наружу, горловина резко переходит в широкое тулово, сужающееся к прогнутому дну. Поверхность темная с пятнами копоти. Диаметр устья 15,4 см, высота 16,2 см, диаметр дна 10,8 см (рис. 3,6).

Погребение 1. Яма трапециевидного очертания ориентирована длинной осью по линии С-Ю. Длина 2,32 м, ширина 1,8 м (северная сторона - 1,2 м, южная сторона $-1,87$ м). На глубине 1,55 м от уровня погребенной почвы, вдоль восточной стенки, оставлена широкая (до 1,05 м) площадка. Высота площадки перед подбоем в западной стенке 0,32 м. По всей видимости, скелет погребенного лежал в узком удлиненном подбое, его кости сдвинуты к западной стенке подбоя (рис. 1,3 ).

Сопровождающий инвентарь:

1. Несколько фрагментов костяной срединной накладки на лук найдены в юго-западной части подбоя. Поверхность пластинки гладкая, ее широкая часть переходит в узкий конец. Длина сохранившейся части пластинки 6,6 см, наибольшая ширина 3,4 см (рис. 3,5).

2. Фрагмент железного черешкового трехлопастного наконечника стрелы обнаружен в южной части дна ямы. На черенке - следы волокон дерева. Длина фрагмента 4,5 см (рис. 3,4$)$.

3. Фрагмент железного предмета неясного назначения встречен в южной части ступеньки.

Погребение относится к позднесарматской культуре. 
Курган 1 был насыпан еще в эпоху поздней бронзы. Именно тогда в степи Волго-Донского междуречья пришли племена срубной культуры. Исследователи полагают, что «исходной территорией» этой общности являлось Самарское Поволжье и районы Волго-Уральского междуречья [Памятники ..., 1993, с. 14].

В проведении погребальных действий при захоронении умершего (погребение 3 - основное в кургане 1) соблюдались обрядовые позиции, характерные именно для раннесрубной (покровской) культуры. Это - глубокая овальная яма, дно которой было покрыто слоем мела и охры, сильная скорченность тела, следы охры на отдельных костях скелета, восточная ориентировка головой и сравнительно большой сопровождающий инвентарь: фрагменты от трех сосудов и фрагмент от крупного кухонного котла (жаровня?), кости жертвенного животного - барана.

Следует отметить, что северо-западная часть ямы была перекрыта жердями, на которые уложили плотный слой прутьев с листьями и слой тогда еще зеленой куги. На это перекрытие была поставлена часть сосудов. Некоторые из них провалились после гниения жердей в яму погребения: их фрагменты встречены на разной глубине в засыпи. Древние четко соблюдали обряд погребения уважаемого человека, для которого не только была вырыта глубокая яма, но и оформлена поминальная тризна - раскладка большого слоя зеленых растений, на которых могли разместиться приглашенные к поминовению. Как говорится в гимнах Ригведы: «Садитесь на жертвенную солому: приготовлено широкое место...» [Ригведа ..., 1999, с. 103].

Аналогии такому поминальному ритуалу в южных районах Волго-Донского междуречья единичны. Пример - большой одиночный курган у р.п. Новониколаевский (Волгоградская область, бассейн р. Хопер). Здесь большая прямоугольная яма погребения-кенотафа была перекрыта плахами, прутьями и кугой. На дне ямы стояли крупный острореберный орнаментированный сосуд и небольшой баночный сосуд, лежали несколько костей барана. На вершине первичной насыпи была устроена обширная прямоугольная наброска куги и камыша. У основания насыпи вырыли ритуальную яму (в засыпи - пепел и угольки), перекрытую крупными плахами. После чего весь этот сложный поминальный комплекс покрыли второй насыпью.

Погребение 3 из кургана 1 относится к периоду появления населения эпохи поздней бронзы, которое определяется по характерным элементам как покровское. Именно оно ляжет потом в основу формирующейся в XVIIXVI вв. до н. э. срубной культуры [Малов, 1994, c. 10].

Позднее в верхние насыпи кургана были впущены погребения срубной культуры 1 и 2 , разрушенные глубокой пахотой.

В эпоху раннего железного века около кургана 1 появились две небольшие насыпи (курганы 2 и 3), сооруженные индивидуально над каждым погребением позднесарматской культуры. А.С. Скрипкин считает, что появление сарматских племен этой поры в ВолгоДонских степях можно датировать первой половиной II в. [Скрипкин, 1990, с. 221]. Полагаем, что погребение 1 из кургана 2 было наиболее ранним из них.

Погребенный покоится в овальной катакомбе, вырытой параллельно овальному же входу (рис. 1,2). При рытье ниши, вероятно, не учли высокий рост умершего, поэтому его положили на спину, несколько изогнув тело по дуге. А.С. Скрипкин назвал такие сооружения катакомбными и отнес их к варианту Г [Скрипкин, 1990, с. 277, рис. 51]. Погребенный положен головой на юг (продолжение традиции среднесарматского периода?). Это не характерно для памятников позднесарматской культуры (с северной ориентировкой). Следует отметить следы искусственной деформации черепа - признак «массового явления» известен уже во II в. н. э. [Степи европейской части ..., 1989, с. 192]. Прослеживается культ огня - слой пепла и угольков на приступке у входа в катакомбу.

В погребении найдена посуда: местная, лепная (рис. 3,1 ) и импортная (рис. $2,4,5$ ), привезенная из мастерских Нижнего Дона, Кубани, Северного Кавказа и Причерноморья [Мамонтов, 2009, с. 328]. Кувшин с высокой горловиной и реповидным туловом имел короткую ручку, изготовленную из глиняного жгута. Она соединяла горловину с верхней частью тулова. На ручке имеется небольшой уступ. Именно в этом месте мастера стали 
формировать из глины нечто, напоминающее голову и туловище животного. То есть кувшин, учитывая его форму, вполне можно отнести к категории небольших сосудов, где встречается зооморфная ручка. Сосуды с зооморфной ручкой использовались кочевниками-сарматами во II-IV вв. н. э. [Абрамова, 1969, с. 74, 79].

Миска из погребения 1 кургана 2 (рис. 2,5) относится к VIII типу (по А.С. Скрипкину), широко распространенному в сарматской кочевой среде в III в н. э. [Скрипкин, 1984, c. 30]. Абрамова М.П. пологает, что миски подобного типа «являются предметами северокавказского импорта» и часто встречаются в погребениях сарматов II-III вв. [Абрамова, 1979, с. 47].

Полевые гончарные мастерские на зимних становищах полностью обеспечивали кочевников посудой местного производства. Она чаще представлена в погребениях округлобо- кими сосудами с коротким венчиком. Такие горшки находились в погребениях поздних сарматов в курганах 2 (рис. 3,1 ) и 3 (рис. 3,6 ) Антоновского могильника.

Погребение 1 из кургана 3 полностью разрушено грабительским перекопом. Сопровождающий материал довольно скромен. В засыпи ямы, среди разбросанных по дну подбоя костей скелета были: фрагменты лепного сосуда местного производства (рис. 3,6), жаровня из дна крупного хозяйственного сосуда (рис. 3,8), фрагменты портупейного кольца (рис. 3,2 ), ножа (рис. 3,3), железного наконечника стрелы (рис. 3,4), а также фрагмент костяной пластинки-накладки на лук (рис. 3,5 ). Последняя напоминает накладки на луки «гуннского» типа, близкого накладкам восточноевропейских образцов этого стрелкового оружия, которые датируются II-III вв. [Гугуев, Безуглов, 1990 , с. 166 , рис. 2,10 ; с. 171]. 


\section{ИЛЛЮСТРАЦИИ}

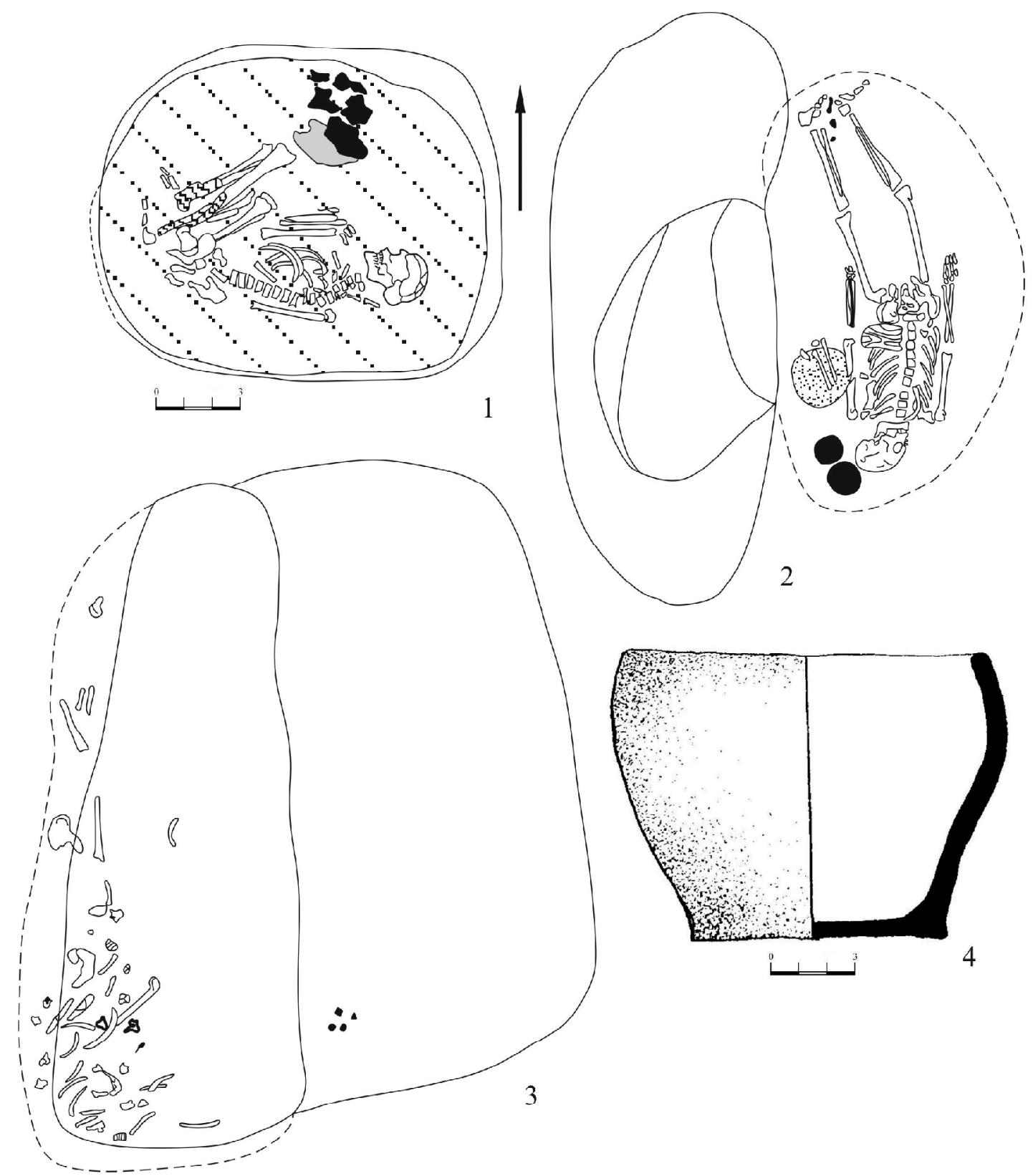

Рис. 1. Планы погребений и инвентарь курганного могильника Антонов II:

1 - погребение 3 кургана 1;2 - погребение 1 кургана 2; 3 - погребение 1 кургана 3; 4 - черноглиняный сосуд из погребения 3 кургана 1 


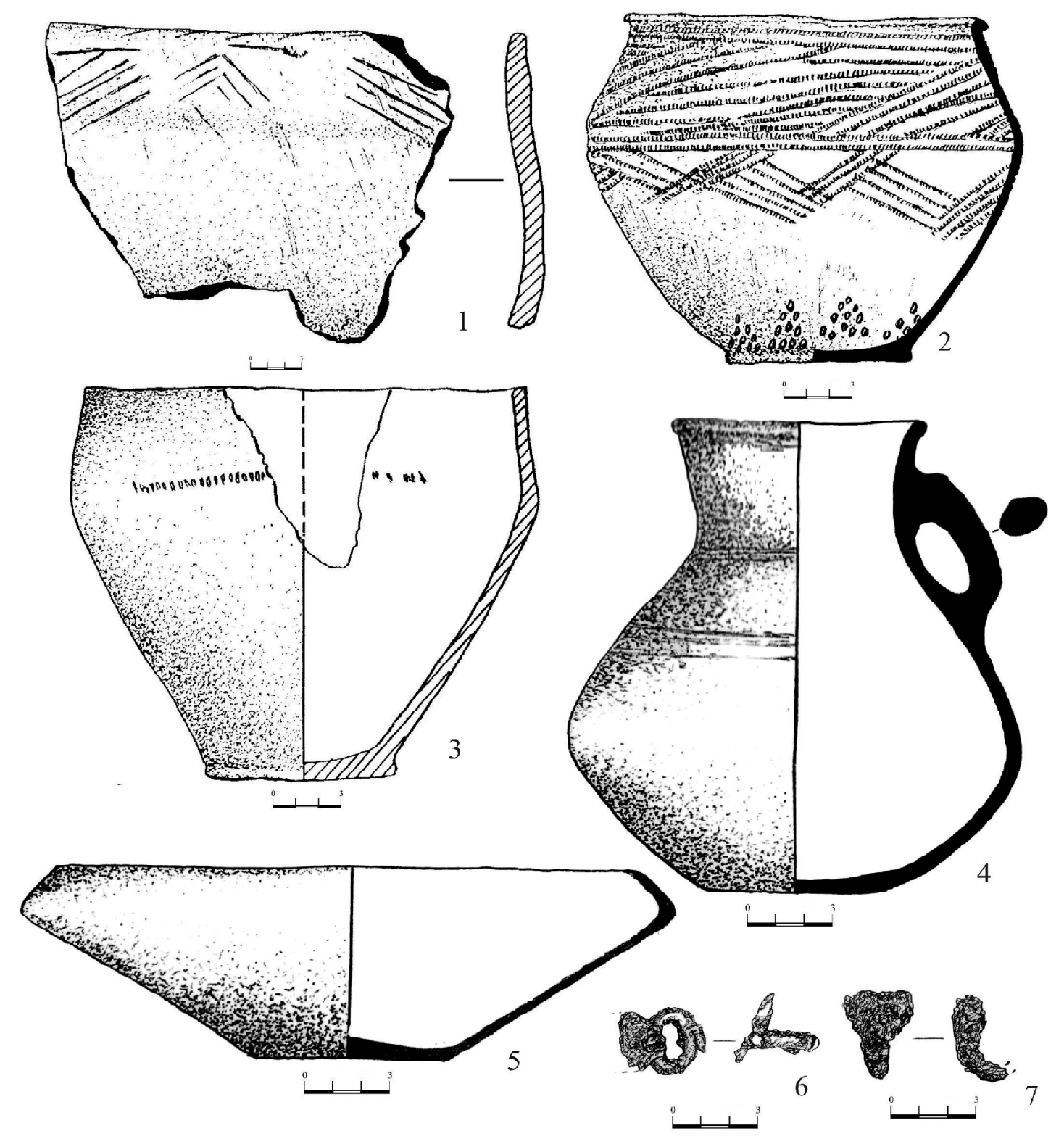

Рис. 2. Инвентарь погребений курганного могильника Антонов II:

1-3 - сосуды из погребения 3 кургана 1; 4-7 - инвентарь из погребения 1 кургана 2

(4 - сероглиняный кувшин, 5 - сероглиняная миска, 6 - железная пряжка, 7 - железный крюк) 



4
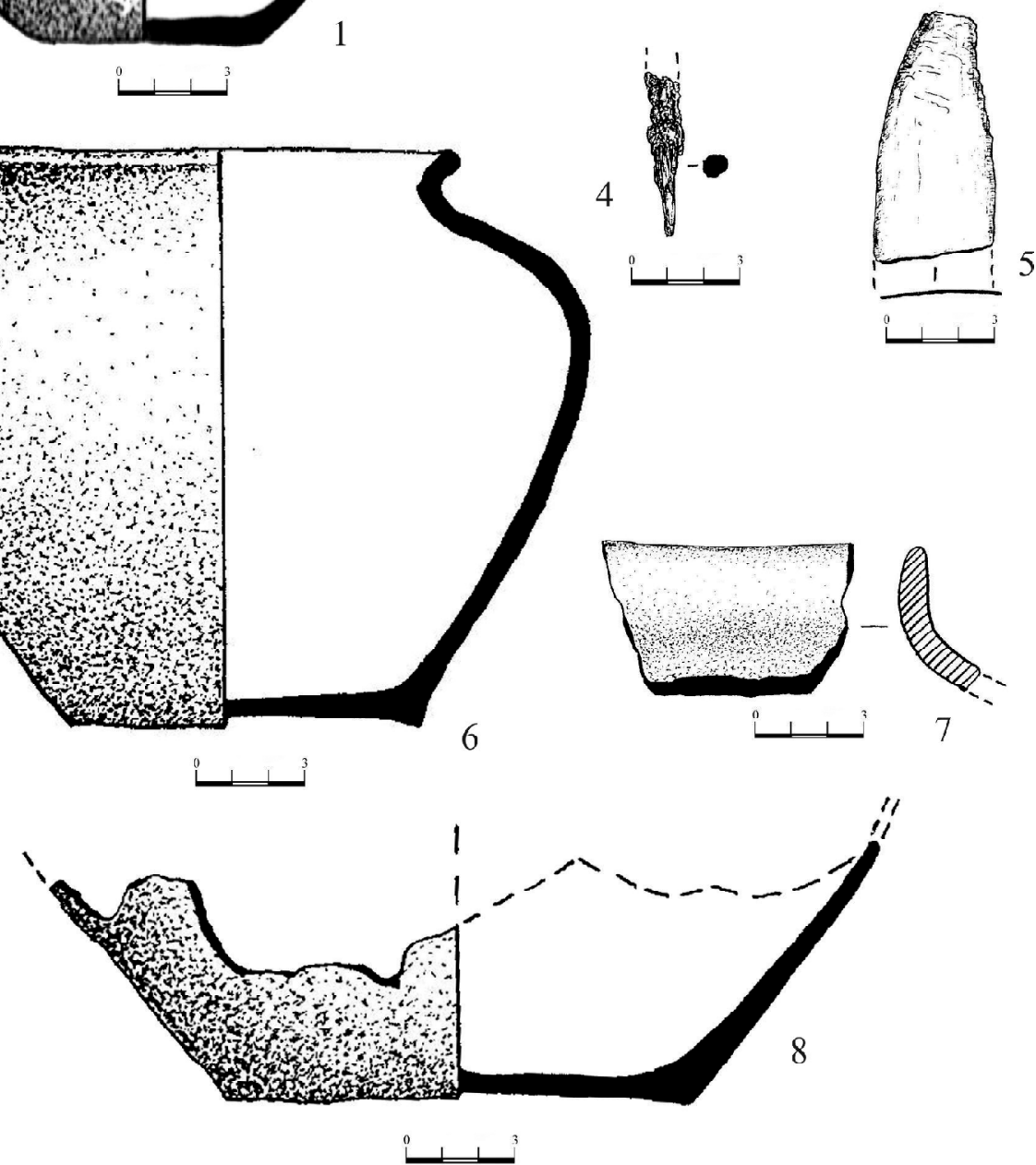

Рис. 3. Вещи из погребений курганного могильника Антонов II:

$1-3$ - инвентарь из погребения 1 кургана 2

( 1 - черноглиняный лепной горшок, 2 - фрагмент железного кольца, 3 - однолезвийный нож); 4-8 - инвентарь из погребения 1 кургана 3

(4 - фрагмент железного наконечника стрелы, 5 - костяная накладка; 6 - черноглиняный сосуд,

7 - фрагмент венчика сероглиняного сосуда, 8 - донная часть лепного сероглиняного сосуда) 


\section{СПИСОК ЛИТЕРАТУРЫ}

Абрамова М. П. (1969). О керамике с зооморфными ручками // СА. № 2. С. 69-84.

Абрамова М. П. (1979). К вопросу о связях населения Северного Кавказа сарматского времени // CA. № 2. C. 31-50.

Гугуев В. К., Безуглов С. И. (1990). Всадническое погребение первых веков нашей эры из курганного некрополя Кобякова городища на Дону // СА. № 2. С. 164-175.

Малов Н. М. (1994). Культурные типы памятников срубной культурно-исторической области (концептуальные основы) // Срубная культурно-историческая область. Саратов. C. 8-13.

Мамонтов В. И. (1991). Отчет о работе Приволжского отряда ЛОИА АН СССР и Донской экспедиции Волгоградского пединститута в 1991 г. // Архив ВОКМ. № 106.

Мамонтов В. И. (1992). Отчет о работе Приволжского отряда ИИМК РАН и Донской экспедиции НИС ВГПУ в 1992 г. // Архив ВОКМ. № 84 .

Мамонтов В. И. (1994). Элитные погребения срубной культуры степной части Волго-Донского междуречья // Срубная культурно-историческая область. Саратов. С. 80-83.

Мамонтов В. И. (2009). Сарматские курганы могильника Первомайский XIV // Нижневолжский археологический вестник. Волгоград. Вып. 10. C. 328-334.

Памятники срубной культуры. Волго-Уральское междуречье (1993) //Археология России. САИ. Саратов. B1-10. 200 c.

Ригведа: Мандалы I-IV (1999) / отв. ред. П. А. Гринцер. М. : Наука. 768 с.

Скрипкин А. С. (1984). Нижнее Поволжье в первые века нашей эры. Саратов. 150 с.

Скрипкин А. С. (1990). Азиатская Сарматия. Саратов. 299 с.

Степи европейской части СССР в скифо-сарматское время (1989) // Археология СССР. М. 464 с.

\section{REFERENCES}

Abramova M.P. (1969). About the pottery with zoomorphic handles. Soviet archaeology, no. 2, pp. 69-84. (in Russian).

Abramova M.P. (1979). To the question about the relations of the population of the North Caucasus Sarmatian time. Soviet archaeology, no. 2, pp. 31-50. (in Russian).

Guguev V.K., Bezuglov S.I. (1990). Equestrian burial of the first centuries of our era from the barrow necropolis of Kobyakovo settlement on the Don river. Soviet archaeology, no. 2, pp. 164-175. (in Russian).

Malov N.M. (1994). Types of cultural monuments of carcass culturally-historical region (the conceptual framework). Carcass culturallyhistorical region. Saratov, pp. 8-13. (in Russian).

Mamontov V.I. (1991). Report on the work of the Volga detachment of LOIA of the USSR and the Don expedition of the Volgograd pedagogical Institute in 1991. Archive of VOKM, no. 106. (in Russian).

Mamontov V.I. (1992). Report on the work of the Volga detachment of the IIMK RAS and the Don expedition of NIS PhD in 1992. Archive of VOKM, no. 84. (in Russian).

Mamontov V.I. (1994). An elite burial of the carcass culture of the steppe part of the Volga-Don interfluve. Carcass culturally-historical region. Saratov, pp. 80-83. (in Russian).

Mamontov V.I. (2009). Sarmatian barrows of the Pervomayskaya XIV burial ground. The Lower Volga archaeological bulletin, Volgograd, iss. 10, pp. 328-334. (in Russian).

Monuments of log culture. Volga-Don interfluve. (1993). Archaeology of Russia. Collection of archaeological sources, Saratov, iss. V1-10.200 p. (in Russian).

Rigveda: Mandalas I-IV (1999). Moscow, Nauka Publ. 768 p. (in Russian).

Skripkin A.S. (1984). The Lower Volga region in the first centuries of our era. Saratov. 150 p. (in Russian).

Skripkin A.S. (1990). Asian Sarmatia. Saratov. 299 p. (in Russian).

Steppes of the European part of the USSR in the Scythian-Sarmatian time (1989). Archaeology of the USSR. Moscow. 464 p. (in Russian). 


\section{Information about the Authors}

Vladislav I. Mamontov, Candidate of Sciences (History), Associate Professor, Professor of Department of History of Russia, Head of Scientific and Industrial Laboratory of Archaeology and Restoration, Volgograd State Socio-Pedagogical University, Prosp. Lenina, 27, 400066 Volgograd, Russian Federation, legenda@vspu.ru.

Vasiliy V. Mataev, Candidate of Sciences (Pedagogy), Specialist-Archaeologist, Archaeological expedition Ltd., Kolkhozny Cross., 11a, 346580 Rodionovo-Nesvetayskaya Village, Rostov Region, Russian Federation, legenda@vspu.ru.

\section{Информация об авторах}

Владислав Иванович Мамонтов, кандидат исторических наук, доцент, профессор кафедры истории России, заведующий научно-производственной лабораторией археологии и реставрации, Волгоградский государственный социально-педагогический университет, просп. им. В.И. Ленина, 27, 400066 г. Волгоград, Российская Федерация, legenda@vspu.ru.

Василий Владимирович Матаев, кандидат педагогических наук, специалист-археолог, ООО «Археологическая экспедиция», пер. Колхозный, 11а, 346580 сл. Родионово-Несветайская, Ростовская область, Российская Федерация, legenda@vspu.ru.

Citation. Mamontov V.I., Mataev V.V. (2016). Antonov II Burial Mound. The Lower Volga Arhaeological Bulletin, vol. 15, no. 1, pp. 116-125. (in Russian). 